\title{
Synthesis and electrochemical properties of benzyl- mercapto and dodecyl-mercapto tetrasubstituted manganese phthalocyanine complexes
}

\author{
Bolade Agboola $^{a}$, Kenneth I. Ozoemena ${ }^{b, 1}$, Philippe Westbroek ${ }^{\mathrm{c}}$ and Tebello \\ Nyokong ${ }^{\text {a, } 1}$

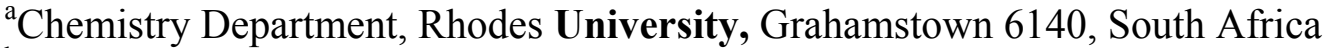 \\ ${ }^{\mathrm{b}}$ Chemistry Department, University of Pretoria, Pretoria 0002, South Africa \\ ${ }^{\mathrm{c}}$ Department of Textiles, Ghent University, Technologiepark 907, B-9052 Gent, Belgium
}

\begin{abstract}
Manganese tetrakis (benzyl-mercapto) phthalocyanine (MnTBMPc) and manganese tetrakis (dodecyl-mercapto) phthalocyanine (MnTDMPc) complexes were synthesized and their spectral and electrochemical properties are reported. Cyclic voltammetric data showed three reversible to quasi-reversible and two irreversible redox processes for both complexes. Ring substituents influenced the positions of both oxidation and reduction redox couples. Spectroelectrochemistry confirmed the first two reductions to be due to $\mathrm{Mn}^{\text {III }} \mathrm{Pc}^{2-} / \mathrm{Mn}^{\text {II }} \mathrm{Pc}^{2-}$ and $\mathrm{Mn}^{\text {II }} \mathrm{Pc}^{3-} / \mathrm{Mn}^{\text {II }} \mathrm{Pc}^{2-}$ processes. The first example of a formation of self-assembled monolayers (SAMs) using thiol substituted MnPc complexes is presented, the SAMs were found to show blocking characteristics towards some faradaic reactions.
\end{abstract}

\section{Article Outline}

1. Introduction

2. Experimental

2.1. Materials and reagents

2.2. Apparatus and procedure

2.3. Synthesis

2.3.1. Manganese(III)acetate tetrakis (benzyl-mercapto) phthalocyanine, $\mathrm{Mn}(\mathrm{OAc}) \mathrm{TBMPc}$, complex 3a

2.3.2. Manganese(III)acetate tetrakis (dodecyl-mercapto) phthalocyanine, $\mathrm{Mn}(\mathrm{OAc}) \mathrm{TDMPc}$, complex $\mathbf{3 b}$

2.4. Procedure for self-assembled monolayers formation

3. Results and discussion

3.1. Synthesis and spectral characterisation

3.2. Voltammetric and spectroelectrochemical studies 
3.3. Formation of self-assembled monolayers (SAMs)

4. Conclusion

Acknowledgements

References

\section{Introduction}

Metallophthalocyanine (MPc) complexes are traditionally used as dyes and pigments. They have attracted a lot of research interest due to their unique physico-chemical properties and nowadays they are being used in various research areas such as photosensitization in photodegradation of pollutants [1], [2] and [3] and photodynamic therapy (PDT) [4] and [5], and in non-linear optics [6]. They have also been found to be useful in electrode modification for use as electrocatalysts and electrochemical sensors. Thiol-derivatised MPc complexes are employed for the modification of gold electrodes by the self-assembled monolayer (SAM) technique [7], [8] and [9]. However, the number of MPc complexes substituted with thiols is still limited and the electrochemistry of these molecules has not been fully explored, this is due to the fact that the synthesis of thiolderivatised metallophthalocyanines is tedious and requires toxic chemical reagents.

Manganese phthalocyanine complexes have very interesting electrochemistry due to the fact that manganese metal exhibits variable oxidation states ranging from $\mathrm{Mn}^{\mathrm{I}}$ to $\mathrm{Mn}^{\mathrm{IV}}$ in MPc complexes [10], [11], [12], [13] and [14]. This makes manganese phthalocyanine complexes potential catalysts for many reactions. Substituted manganese phthalocyanine complexes are still relatively few, and their electrochemistry not fully understood, compared to other first row transition metal metallophthalocyanine complexes. For example, the first reduction in $\mathrm{Mn}^{\mathrm{II}} \mathrm{Pc}^{2-}$ complexes has been a subject of some controversy, with some reports proposing ring reduction to the $\mathrm{Mn}^{\mathrm{II}} \mathrm{Pc}^{3-}$ species and others suggesting metal reduction to the $\mathrm{Mn}^{\mathrm{I}} \mathrm{Pc}^{2-}$ species [15]. Also the formation of SAMs using thiol substituted MnPc complexes has not been reported. In this work we report on the synthesis and electrochemistry of MPc complexes tetrasubstituted with benzyl-mercapto (3a) and dodecyl-mercapto (3b) groups as the ring substituents (Scheme 1), and for the first time report on the formation of SAMs using thiol substituted $\mathrm{MnPc}$ complexes. These substituents are chosen in order to show the effects of long alkyl chain versus the benzene ring on the electrochemical properties. The electrochemical data will be compared with that of other MnPc complexes shown in Fig. 1. 


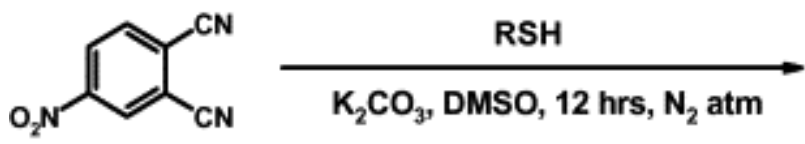

[1]<smiles>N#Cc1ccc(Br)cc1C#N</smiles>

[2]

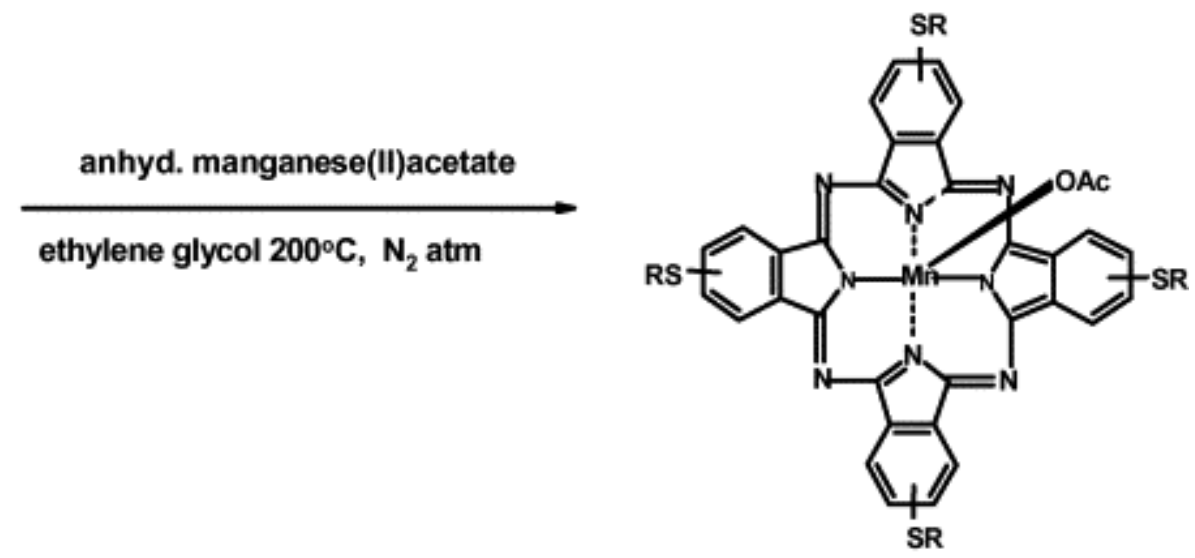<smiles>[R]=C1C=CC(Cc2ccccc2)C1</smiles>

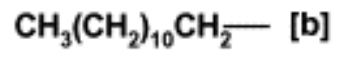

Scheme 1. Synthetic route for thiol-derivatised metallophthalocyanines complexes. Complex 3a, manganese(III)acetate tetrakis (benzyl-mercapto) phthalocyanine, MnTBMPc. Complex 3b, manganese(III)acetate tetrakis (dodecyl-mercapto) phthalocyanine, MnTDMPc.<smiles>OCCc1cccs1</smiles>

$\mathrm{NH}_{2}$
(4)

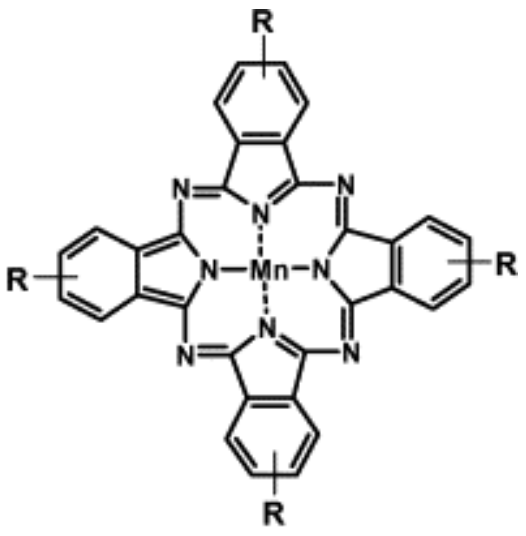

Fig. 1. General representation of the molecular structures of the manganese phthalocyanine complexes. 


\section{Experimental}

\subsection{Materials and reagents}

4-Nitrophthalonitrile, 4-(benzyl-mercapto) phthalonitrile and 4-dodecylmercaptophthalonitrile were synthesized according to procedure in literature [16] and [17]. Potassium carbonate and manganese(II)acetate salts were obtained from SigmaAldrich and were used as received. Tetrabutylammonium tetrafluoroborate $\left(\mathrm{TBABF}_{4}\right)$ (Aldrich) was used as an electrolyte for electrochemical experiments. Ethylene glycol, dimethylsulfoxide (DMSO), tetrahydrofuran (THF), dichloromethane (DCM), chloroform, methanol and ethanol were distilled prior to use. Silica gel $60(0.04-$ $0.063 \mathrm{~mm}$ ) for column chromatography was purchased from Merck. For SAM characterisation, phosphate buffers were used for $\mathrm{pH}$ studies. All solutions used were dearated by bubbling nitrogen prior to the experiments and the electrochemical set-up was kept under nitrogen atmosphere throughout the experiments.

\subsection{Apparatus and procedure}

UV-vis absorption spectra were recorded on a Varian 500 UV-vis/NIR spectrophotometer. FTIR spectra (KBr pellets) were recorded on a Perkin-Elmer spectrum 2000 FT-IR spectrometer. MALDI-TOF spectra were obtained with Perspective Biosystems Voyager DE-PRO Biospectrometry Workstation and possessing Delayed Extraction at the University of Cape Town, South Africa. Elemental analyses were performed by University of Cape Town, South Africa. For the electrochemical characterisation of the manganese phthalocyanines complexes, cyclic voltammetry (CV) and square wave voltammetry (SWV) were carried out using Autolab potentiostat PGSTAT 30 (Eco Chemie, Utretch, The Netherlands) driven by the General Purpose Electrochemical Systems data processing software (GPES, software Version 4.9, Eco Chemie). A three-electrode set-up that consisted of a glassy carbon working electrode (GCE, $3.0 \mathrm{~mm}$ diameter), $\mathrm{Ag} \mid \mathrm{AgCl}$ wire pseudo reference electrode and platinum wire counter electrode was employed. Square wave parameters were: step potential $5 \mathrm{mV}$; amplitude $20 \mathrm{mV}$ at a frequency of $25 \mathrm{~Hz}$. Spectroelectrochemical data were obtained using a home made optically transparent thin-layer electrochemical (OTTLE) cell which was connected to a Bioanalytic Systems (BAS) CV 27 voltammograph. The design of the OTTLE cell was similar to that reported in literature [18]. For the study of self-assembled monolayers of the complexes on gold electrodes, Advanced Electrochemical System (Princeton Applied Research) PARSTAT 2273 equipment was employed with a threeelectrode set-up consisting of either bare gold $(r=0.8 \mathrm{~mm}$, BAS) or MPc-SAM modified gold electrodes, $\mathrm{Ag} \mid \mathrm{AgCl}(\mathrm{NaCl}$, saturated) reference electrode and platinum wire counter electrode.

\subsection{Synthesis}

The synthetic route employed in this work is shown in Scheme 1. 


\subsubsection{Manganese(III)acetate tetrakis (benzyl-mercapto) phthalocyanine, Mn(OAc)TBMPc, complex 3a}

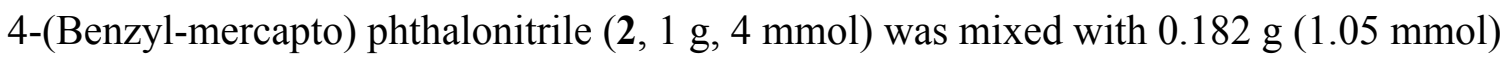
anhydrous manganese(II)acetate and $6 \mathrm{ml}$ ethylene glycol and then refluxed for $5 \mathrm{~h}$ at $200{ }^{\circ} \mathrm{C}$ under $\mathrm{N}_{2}$ atmosphere. The mixture was allowed to cool to room temperature and then excess methanol was added to precipitate out the crude reddish brown solid product which was then treated in a Soxhlet extraction apparatus with ethanol for $48 \mathrm{~h}$. The product was purified using silica gel column chromatography eluting twice with chloroform and THF. The pure complex was a deep red solid. Yield: $48 \%$. IR (KBr) $v$ $\left(\mathrm{cm}^{-1}\right): 865\left(v_{\mathrm{Mn}} \mathrm{O}\right), 1743\left(v_{\mathrm{C}=0}\right) \cdot \lambda_{\max }(\mathrm{nm})(\log \varepsilon)$ in DCM: $745(5.1), 526(4.8), 452$ (4.4). Anal. Calcd. for $\mathrm{C}_{60} \mathrm{H}_{40} \mathrm{~N}_{8} \mathrm{~S}_{4} \mathrm{Mn}: \% \mathrm{C}, 66.79 ; \% \mathrm{H}, 3.86 ; \% \mathrm{~N}, 10.06$. Found: $\% \mathrm{C}$, 66.07; \%H, 4.18; \%N, 10.26. MALDI-TOF: $\mathrm{C}_{62} \mathrm{H}_{43} \mathrm{~N}_{8} \mathrm{~S}_{4} \mathrm{O}_{2} \mathrm{Mn}$. Calcd. $1054.9 \mathrm{~g} / \mathrm{mol}$, found $\left(\mathrm{M}^{+}\right) 1054.3 \mathrm{~g} / \mathrm{mol}$.

\subsubsection{Manganese(III)acetate tetrakis (dodecyl-mercapto) phthalocyanine, Mn(OAc)TDMPc, complex 3b}

The procedure and the amounts of reagent were the same as for 3a except 4-dodecylmercaptophthalonitrile (2b) was employed instead of $2 \mathbf{a}$ and $4 \mathrm{~h}$ reaction time (instead of $5 \mathrm{~h})$ was employed. Yield: $41 \%$. IR $(\mathrm{KBr}) v\left(\mathrm{~cm}^{-1}\right): 857\left(v_{\mathrm{Mn}} \mathrm{O}\right), 1765\left(v_{\mathrm{C}}=0\right)$. $\lambda_{\max }(\mathrm{nm})(\log \varepsilon)$ in DCM: 749 (4.9), 528 (4.6), 450 (4.3). Anal. Calcd. for $\mathrm{C}_{80} \mathrm{H}_{112} \mathrm{~N}_{8} \mathrm{~S}_{4} \mathrm{Mn}: \% \mathrm{C}, 69.01 ; \% \mathrm{H}, 8.07 ; \% \mathrm{~N}, 7.86$. Found: \%C, 70.22; \%H, 7.98; \%N, 6.84. MALDI-TOF: $\mathrm{C}_{82} \mathrm{H}_{115} \mathrm{~N}_{8} \mathrm{~S}_{4} \mathrm{O}_{2} \mathrm{Mn}$ : Calcd. $1370.9 \mathrm{~g} / \mathrm{mol}$, found $\left(\mathrm{M}^{+}\right) 1370.5 \mathrm{~g} / \mathrm{mol}$.

\subsection{Procedure for self-assembled monolayers formation}

The gold electrodes were polished with slurries of alumina of different particle sizes (1.0 and $0.3 \mu \mathrm{m}$ ) on a SiC-emery paper (type 2400 grit) and thereafter subjected to ultrasonic vibration in ethanol in order to remove residual alumina particles at the gold electrode surface. The gold electrodes were treated with 'Piranha' solution ( $1: 3$, v/v, $30 \% \mathrm{H}_{2} \mathrm{O}_{2}$ and concentrated $\mathrm{H}_{2} \mathrm{SO}_{4}$ ) for about 1 min (this step removes the organic contaminants by destructive oxidation), followed by thorough rinsing with distilled water. The gold electrodes were then rinsed with ethanol and finally with the dichloromethane (DCM) which is the deposition solvent. Following this pre-treatment, the electrodes were then placed in nitrogen-saturated $1 \mathrm{mM}$ solutions of the MnPcs in DCM. The SAMs were allowed to form for $18 \mathrm{~h}$ and thereafter the modified electrodes were thoroughly rinsed with DCM, dried gently in a weak flowing nitrogen gas and stored in nitrogen-saturated phosphate buffer $\mathrm{pH} 4.0$ at room temperature.

\section{Results and discussion}

\subsection{Synthesis and spectral characterisation}

Manganese tetrakis (benzyl-mercapto) phthalocyanine (MnTBMPc, 3a) and manganese tetrakis (dodecyl-mercapto) phthalocyanine (MnTDMPc, $\mathbf{3 b}$ ) complexes were 
characterized using spectroscopic methods such as IR and UV-vis spectroscopy, also using MALDI-TOF mass spectra and elemental analysis. All methods showed satisfactory results. Both complexes are deep red in colour due to absorption in the 400$500 \mathrm{~nm}$ region and the red shift of the $\mathrm{Q}$ band, typical of $\mathrm{Mn}^{\mathrm{III}} \mathrm{Pc}$ complexes [13], [14] and [19], Fig. 2. The UV-vis bands at 452 and $526 \mathrm{~nm}$ for MnTBMPc, 3aand at 450 and $528 \mathrm{~nm}$ for MnTDMPc, $\mathbf{3 b}$ are charge transfer bands between metal and ligand. IR bands at 865 and $857 \mathrm{~cm}^{-1}$ correspond to $\mathrm{Mn}^{\mathrm{III}}$ _ O vibration from the bond between $\mathrm{Mn}^{\mathrm{III}}$ and the axial acetate ligand for complexes $\mathbf{3 a}$ and $\mathbf{3 b}$, respectively. Both complexes showed the $\mathrm{C}=\mathrm{O}$ bands of the acetate ion at 1743 and $1765 \mathrm{~cm}^{-1}$, respectively. MALDI-TOF spectra showed the complexes without the acetate residue though the reason could not be ascertained but similar observation has been reported before [19]. Elemental analysis of both complexes gave satisfactory results corresponding to the $\mathrm{Mn}(\mathrm{OAc}) \mathrm{Pcs}$.

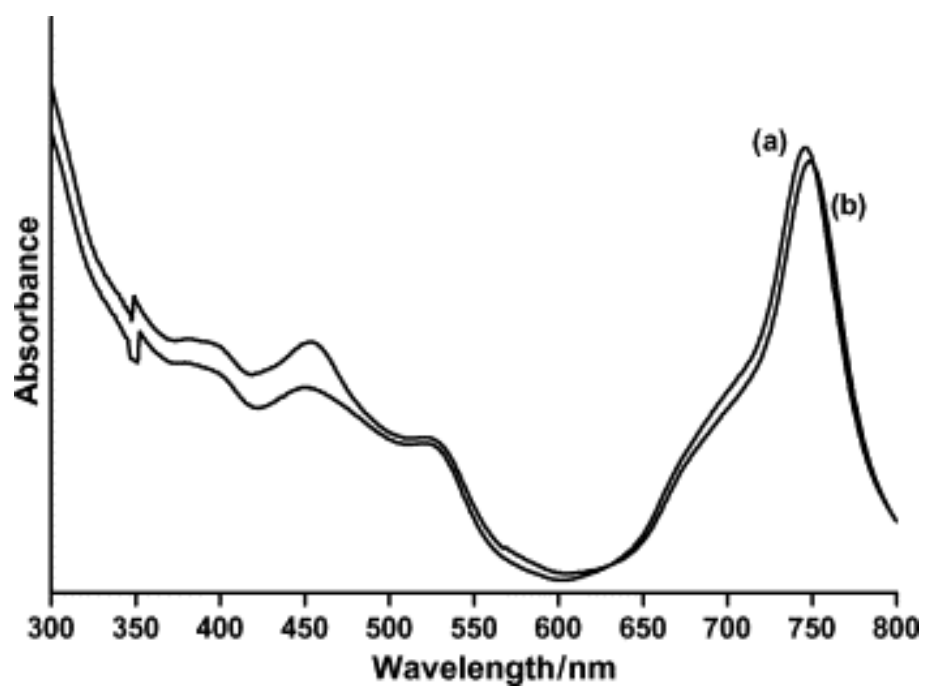

Fig. 2. UV-vis spectra of MnTBMPc, 3a (a) and MnTDMPc, 3b (b) in DMF. Concentrations: $1 \times 10^{-6} \mathrm{~mol} \mathrm{dm}^{-3}$.

Both complexes were found to be soluble in less polar solvents such as DCM and chloroform while only complex 3a which has benzyl-mercapto group as the ring substituents dissolved in the more polar solvents such as DMSO and DMF. The nonsolubility of complex $\mathbf{3 b}$ in DMSO and DMF was also observed before for MTDMPc $(\mathrm{M}=\mathrm{Fe}, \mathrm{Co}$ and $\mathrm{Ni}$ ) [20] and [21] and was attributed to the presence of the highly nonpolar long dodecylthiol alkyl chains.

\subsection{Voltammetric and spectroelectrochemical studies}

Solution redox properties of the complexes were studied with cyclic voltammetry (CV) and square wave (SWV) voltammetry in DCM using glassy carbon electrode (GCE) as the working electrode. Fig. 3 shows the cyclic voltammograms (inset shows square wave 
voltammograms) of MnTBMPc, 3a and MnTDMPc, 3b complexes in DCM (containing $0.1 \mathrm{M} \mathrm{TBABF}_{4}$ ). Three clear quasi reversible redox processes were observed for both complexes with $\Delta E$ ranging from 100 to $240 \mathrm{mV}$. For MnTBMPc, the redox processes were observed at: $E_{1 / 2}=+1.12 \mathrm{~V}$ (I), $E_{1 / 2}=-0.08 \mathrm{~V}$ (II), $E_{1 / 2}=-0.84 \mathrm{~V}$ (III) versus $\mathrm{Ag} \mid \mathrm{AgCl}$, while for complex MnTDMPc, the three redox couples were observed at: $E_{1 / 2}=+1.06 \mathrm{~V}$ (I), $E_{1 / 2}=-0.26 \mathrm{~V}$ (II), $E_{1 / 2}=-0.98 \mathrm{~V}$ (III) versus Ag|AgCl. A weak irreversible peak was observed near $0.85 \mathrm{~V}$ (labelled $\mathbf{I}^{\prime}$ ) for both complexes. In addition, there is a weak process (labelled with * in Fig. 3) near $0.3 \mathrm{~V}$, which is more clearly seen on the SWV traces. Table 1 compares the half-wave potentials $\left(E_{1 / 2}\right)$ for $\mathbf{3 a}$ and $\mathbf{3 b}$ with those of other thio substituted MnPc complexes (shown in Fig. 1) and of Mn tetraamino phthalocyanine (Fig. 1). In comparison with literature [11], [12] and [14] and with other thio substitituted MnPc complexes, we assign couple II in Fig. 3 (for both complexes) to metal reduction process, $\mathrm{Mn}^{\mathrm{III}} \mathrm{Pc}^{2-} / \mathrm{Mn}^{\mathrm{II}} \mathrm{Pc}^{2-}$. Process III is then assigned to ring reduction, $\mathrm{Mn}^{\mathrm{II}} \mathrm{Pc}^{2-} / \mathrm{Mn}^{\mathrm{II}} \mathrm{Pc}^{3-}$. These assignment will be confirmed below using spectroelectrochemistry. The oxidation of Mn(III) to $\mathrm{Mn}(\mathrm{IV})$ has been observed before [11] for Mn(III) tetraaminophthalocyanine, Table 1 as a weak process, thus, the weak peak near $0.3 \mathrm{~V}$ in Fig. 3, is tentatively assigned to $\mathrm{Mn}^{\mathrm{IV}} \mathrm{Pc}^{2-} / \mathrm{Mn}^{\mathrm{III}} \mathrm{Pc}^{2-}$ process. This process was also observed as a weak peak in Mn tetraamino phthalocyanine. The next two processes $\mathbf{I}^{\prime}$ and $\mathbf{I}$ are in the range for ring [15] oxidation in MPc complexes, Table 1 and are assigned to $\mathrm{Pc}^{-} / \mathrm{Pc}^{2-}$ and $\mathrm{Pc}^{0} / \mathrm{Pc}^{-}$, respectively. Ring oxidation of thiol substituted MPc complexes often results in decomposition [21] hence the lack of reversibility of the oxidation processes (especially $\mathbf{I}^{\prime}$ ). Couple $\mathbf{I}$ is more reversible than $\mathbf{I}^{\prime}$, but it is near the end of the potential range for the system. 

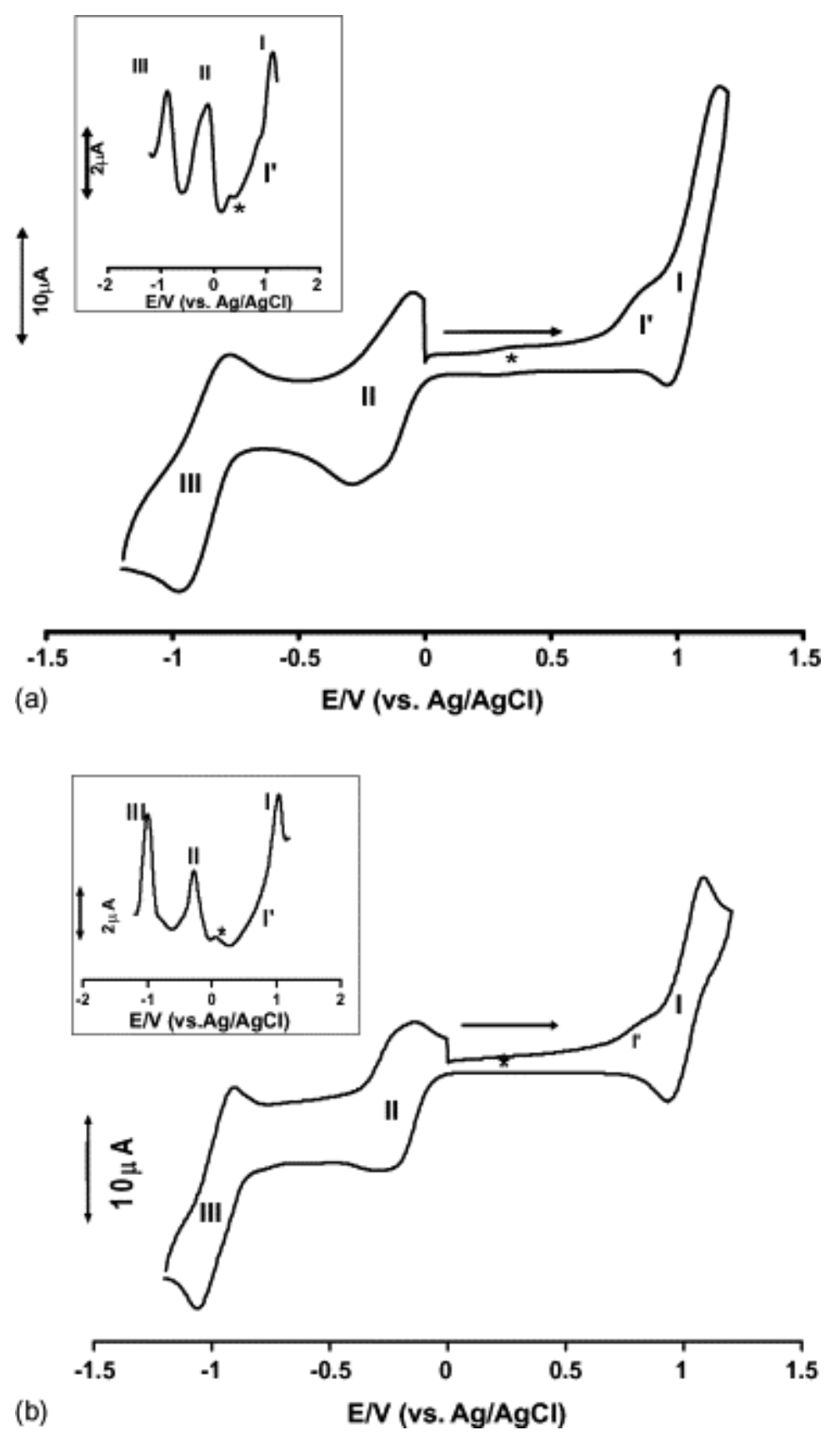

Fig. 3. The cyclic voltammetry of $0.1 \mathrm{mM}$ of (a) complex $\mathbf{3 a}$ and (b) complex $\mathbf{3 b}$ in DCM containing $0.1 \mathrm{M} \mathrm{TBABF}_{4}$. Scan rate $=100 \mathrm{mV} / \mathrm{s}$. Insets: $\mathrm{SWV}$. 
Table 1.

Electrochemical data of $\mathrm{MnPc}$ complexes vs $\mathrm{Ag} / \mathrm{AgCl}$

\begin{tabular}{|c|c|c|c|c|c|c|}
\hline $\begin{array}{l}\text { Com- } \\
\text { plex }\end{array}$ & $\begin{array}{l}\mathrm{Mn}^{\mathrm{II}} \mathrm{Pc}^{2-} / \mathrm{M} \\
\mathrm{n}^{\mathrm{II}} \mathrm{Pc}^{3-} \text { (III) }\end{array}$ & $\begin{array}{l}\mathrm{Mn}^{\mathrm{III}} \mathrm{Pc}^{2-} / \mathrm{Mn}^{\mathrm{II}} \\
\mathrm{Pc}^{2-} \text { (II) }\end{array}$ & $\begin{array}{l}\mathbf{M n}^{\mathrm{IV}} \mathbf{P c}^{2-} / \mathbf{M} \\
\left.\mathbf{n}^{\mathrm{III}} \mathrm{Pc}^{2-}{ }^{*}\right)\end{array}$ & 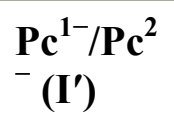 & $\begin{array}{l}\mathbf{P c}^{0^{-}} / \mathbf{P} \\
\mathrm{c}^{1-}(\mathrm{I})\end{array}$ & Reference \\
\hline $3 \mathbf{a}^{\mathrm{a}}$ & -0.84 & -0.08 & $\approx 0.3^{\mathrm{b}}$ & $0.87^{\mathrm{c}}$ & $1.12^{\mathrm{c}}$ & This work \\
\hline $3 b^{a}$ & -0.98 & -0.26 & $\sim 0.3^{b}$ & $0.83^{\mathrm{c}}$ & $1.06^{\mathrm{c}}$ & This work \\
\hline 4 & $-0.68^{\mathrm{b}}$ & -0.06 & - & - & - & 12 \\
\hline 5 & -0.95 & -0.23 & - & 0.75 & 1.16 & 14 \\
\hline 6 & -0.98 & -0.30 & 0.58 & 0.75 & - & 11 \\
\hline
\end{tabular}

Unless otherwise stated, the assignments were confirmed by spectroelectrochemistry data and the solvent is DMF containing $\mathrm{TBABF}_{4}$.

${ }^{\mathrm{a}}$ Data collected in DCM containing $\mathrm{TBABF}_{4}$.

${ }^{\mathrm{b}}$ Assigned to $\mathrm{Mn}^{\mathrm{II}} \mathrm{Pc}^{2-} / \mathrm{Mn}^{\mathrm{I}} \mathrm{Pc}^{2-}$ (but no spectroelectrochemistry data). The subsequent reduction at -1.12 was assigned to $\mathrm{Mn}^{\mathrm{I}} \mathrm{Pc}^{2-} / \mathrm{Mn}^{\mathrm{I}} \mathrm{Pc}^{3-}$.

${ }^{\mathrm{c}}$ Not confirmed using spectroelectrochemistry data.

Introduction of electron-donating groups to MPc ring is expected to lead to a thermodynamically easier oxidation and a more difficult reduction of the MPc complex [22] and [23]. This is because electron-donating group should increase the average electron density of the conjugated $18 \pi$-electron system of the phthalocyanine ring. MnTBMPc, 3a can be said to be more difficult to oxidise than MnTDMPc 3b from the more positive $E_{1 / 2}$ value of its redox couple (I) while MnTDMPc, $\mathbf{3 b}$ is more difficult to reduce than MnTBMPc, 3a from the more negative $E_{1 / 2}$ of its redox couples (II) and (III), Table 1. Aromatic rings are electron donors and hence should be difficult to reduce. However, in complex 3a, the phenyl group is separated from the $\mathrm{Pc}$ ring by a $\mathrm{CH}_{2}$ group, resulting in easier reduction for this complex compared to $\mathbf{3 b}$.

Spectroelectrochemical studies using optically transparent thin-layer electrode (OTTLE) cell gave more insight into the origin of the redox couples observed during voltammetric studies of the complexes. Fig. 4a shows the spectral changes observed during the reduction of MnTBMPc, 3a at potentials of process II. The initial spectrum in Fig. 4a has more aggregated species than the one shown in Fig. 2, this is because a higher concentration of the complex was employed for the spectroelectrochemical studies. Upon reduction, there was a blue shift in the Q band from 742 to $701 \mathrm{~nm}$ and at the same time the colour of the complex changed from red to green, also the charge transfer bands at 523 and $455 \mathrm{~nm}$ decreased in intensity and the latter finally completely disappeared and 
the former shifted from 523 to $533 \mathrm{~nm}$. A shift in the position of the $\mathrm{Q}$ band without a decrease in its intensity is indicative of metal based electroreduction and a blue shift in the $\mathrm{Q}$ band upon reduction is typical of $\mathrm{Mn}^{\mathrm{III}} \mathrm{Pc}^{2-}$ to $\mathrm{Mn}^{\mathrm{II}} \mathrm{Pc}^{2-}$ reduction [15]. Thus, spectral changes in Fig. 4a confirmed that process II is due to the redox couple $\mathrm{Mn}^{\mathrm{III}} \mathrm{Pc}^{2-} / \mathrm{Mn}^{\mathrm{II}} \mathrm{Pc}^{2-}$ ( $n$ was calculated to be approximately 1 from the equation, $\mathrm{Q}=n \mathrm{FVC}$ ). Furthermore, three clear isobestic points at 716, 558 and $402 \mathrm{~nm}$ indicate that it is a clean reduction, that is, only two species were present. Similar spectral changes were observed for 3b, Fig. 5a. As shown in Fig. 4b (for 3a) and Fig. 5b (for 3b), further reduction at potentials of process III resulted in decrease in the intensity of the new Q band and at the same time there was increase in band intensity between 400 and $600 \mathrm{~nm}$ typical of a ring based redox process [24] and [25], for both $\mathbf{3 a}$ and $\mathbf{3 b}$. This observation confirmed that redox couple (III) is a ring based reduction, thus can be assigned to $\mathrm{Mn}^{\mathrm{II}} \mathrm{Pc}^{2-} / \mathrm{Mn}^{\mathrm{II}} \mathrm{Pc}^{3-}$. As stated in Section 1, the first reduction in $\mathrm{Mn}^{\mathrm{II}} \mathrm{Pc}^{2-}$ complexes has been reported to occur either at the ring to form $\mathrm{Mn}^{\mathrm{II}} \mathrm{Pc}^{3-}$ species as observed in this work, while other researchers have suggested metal reduction to the $\mathrm{Mn}^{\mathrm{I}} \mathrm{Pc}^{2-}$ species [15]. Table 1, shows that most substituted MnPc complexes studied show the formation of $\mathrm{Mn}^{\mathrm{II}} \mathrm{Pc}^{3-}$ rather than $\mathrm{Mn}^{\mathrm{I}} \mathrm{Pc}^{2-}$. 

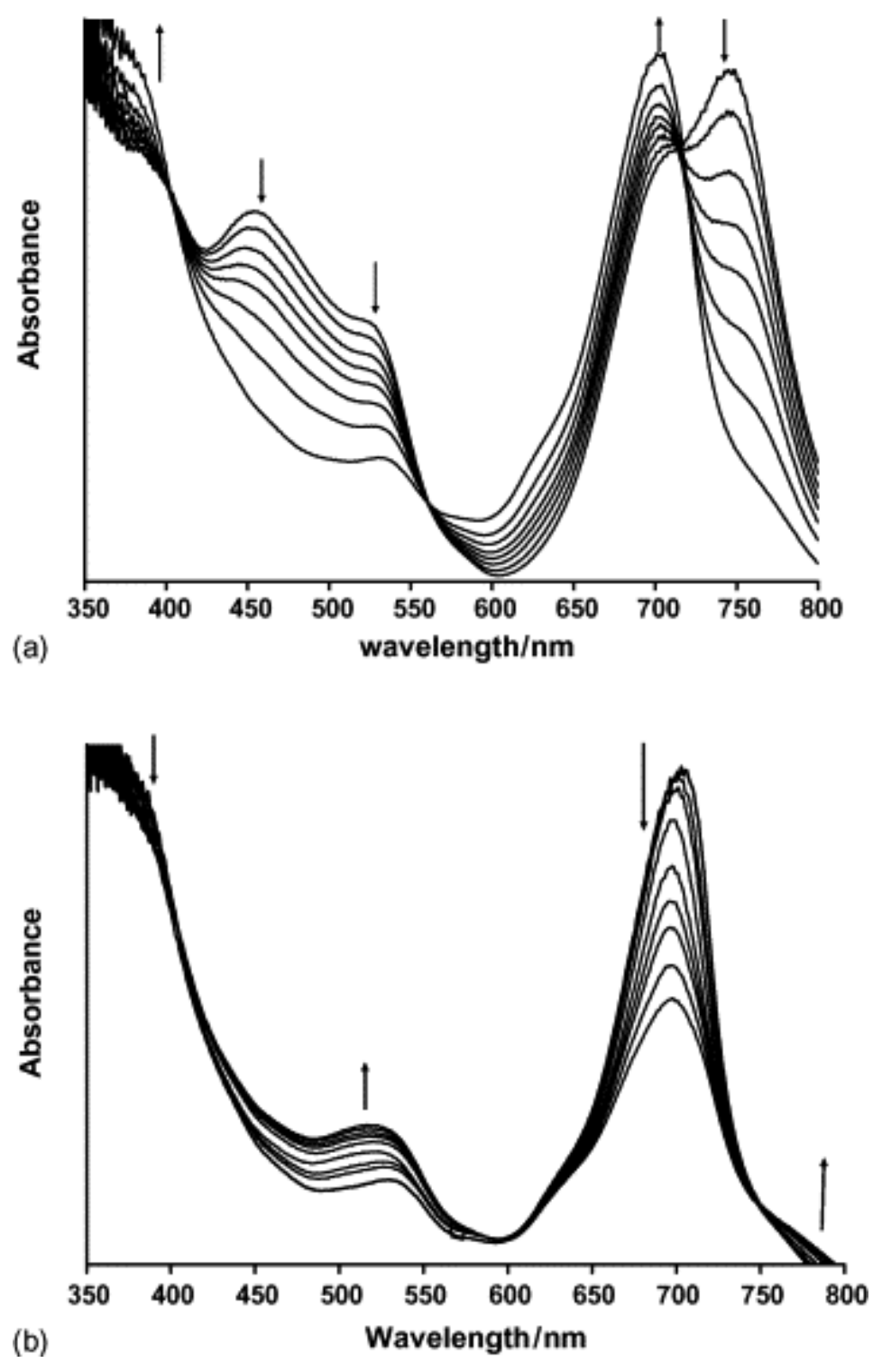

Fig. 4. UV-vis spectral changes for complex 3a observed using controlled potential electrolysis at: (a) $-0.5 \mathrm{~V}$ and (b) $-1.15 \mathrm{~V}$. The electrolyte $=$ DCM containing $0.1 \mathrm{M}$ $\mathrm{TBABF}_{4}$. Electrolysis time was $20 \mathrm{~min}$ for each redox process. 

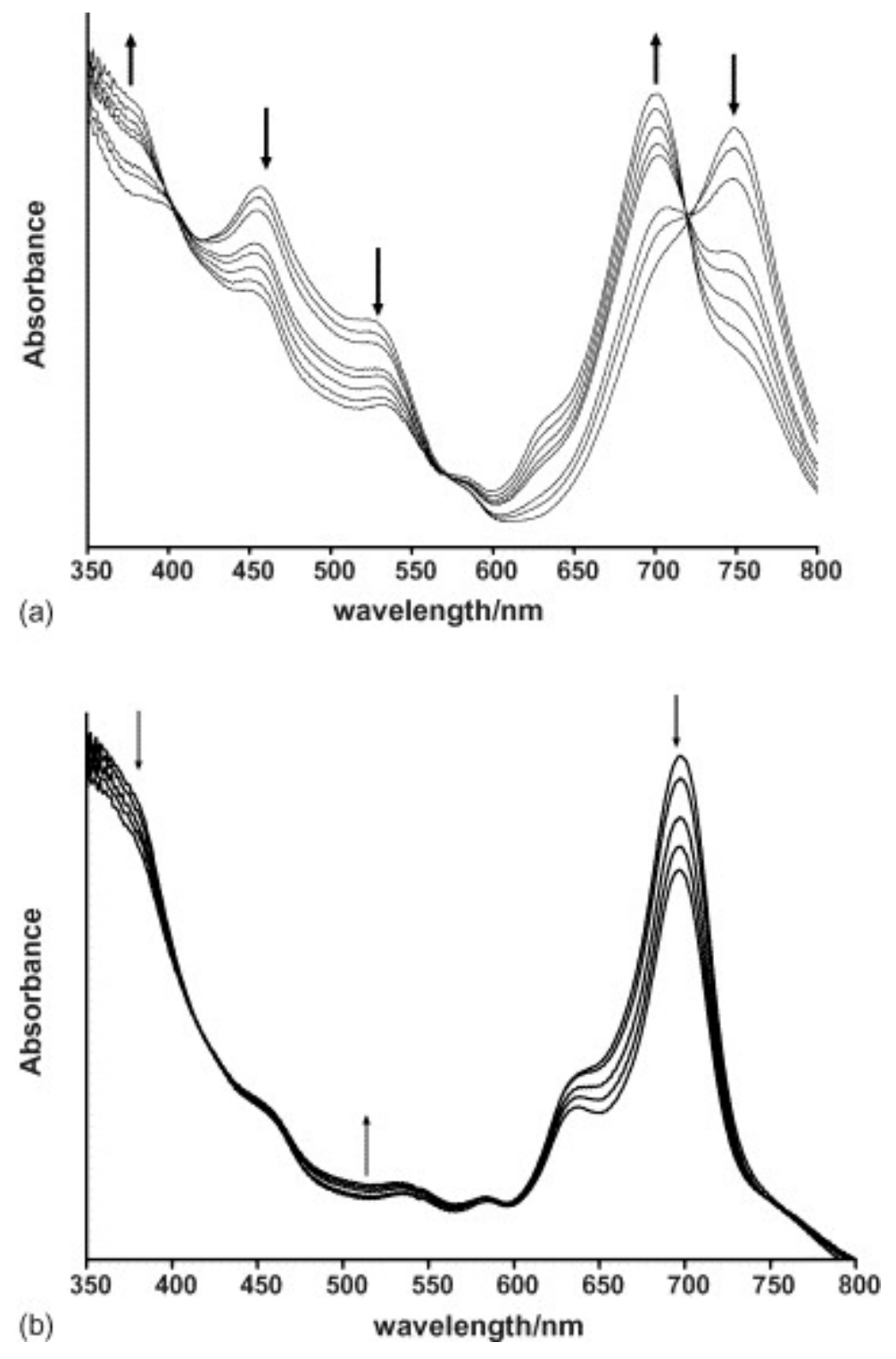

Fig. 5. UV-vis spectral changes for complex $\mathbf{3 b}$ observed using controlled potential electrolysis at: (a) $-0.5 \mathrm{~V}$ and (b) $-1.15 \mathrm{~V}$. The electrolyte $=$ DCM containing $0.1 \mathrm{M}$ $\mathrm{TBABF}_{4}$. Electrolysis time was $20 \mathrm{~min}$ for each redox process.

To confirm origin of the oxidation process, controlled potential electrolysis was conducted using positive potentials (up to $1.2 \mathrm{~V}$ ), no spectral changes associated with oxidation were observed, only a gradual decrease in the Q and B band peak intensities with time was observed indicative of degradation. It is known that for thiol substituted MPc complexes, oxidation is often accompanied by degradation [26].

Based on the electrochemistry data above, we assign the processes I-III as follows: 


$$
\begin{aligned}
& \mathrm{Mn}^{\mathrm{IV}} \mathrm{Pc}^{1-} \rightarrow \mathrm{Mn}^{\mathrm{IV}} \mathrm{Pc}^{0}+\mathrm{e}^{-} \text {(process I) } \\
& \left.\mathrm{Mn}^{\mathrm{IV}} \mathrm{Pc}^{2-} \rightarrow \mathrm{Mn}^{\mathrm{IV}} \mathrm{Pc}^{1-}+\mathrm{e}^{-} \text {(process } \mathrm{I}^{\prime}\right) \\
& \left.\mathrm{Mn}^{\mathrm{III}} \mathrm{Pc}^{2-} \rightarrow \mathrm{Mn}^{\mathrm{IV}} \mathrm{Pc}^{2-}+\mathrm{e}^{-} \text {(process } *\right) \\
& \mathrm{Mn}^{\mathrm{III}} \mathrm{Pc}^{2-}+\mathrm{e}^{-} \rightarrow \mathrm{Mn}^{\mathrm{II}} \mathrm{Pc}^{2-} \text { (process II) } \\
& \mathrm{Mn}^{\mathrm{II}} \mathrm{Pc}^{2-}+\mathrm{e}^{-} \rightarrow \mathrm{Mn}^{\mathrm{II}} \mathrm{Pc}^{3-} \text { (process III) }
\end{aligned}
$$

Eqs. (1), (2)and (3) are only tentatively assigned since the processes could not be confirmed using spectroelectrochemistry, whereas Eqs. (4) and (5) were confirmed.

\subsection{Formation of self-assembled monolayers (SAMs)}

Well established voltametric methods of probing the integrity of SAMs formed were employed in this work. Fig. 6a-c shows the following faradic processes; gold surface oxidation [27], underpotential deposition (UPD) of copper [28] and solution redox chemistry $\left[\mathrm{Fe}\left(\mathrm{H}_{2} \mathrm{O}\right)_{6}\right]^{3+} /\left[\mathrm{Fe}\left(\mathrm{H}_{2} \mathrm{O}\right)_{6}\right]^{2+}[29]$. The gold surface oxidation reaction was almost totally inhibited by the MnPcs-gold electrodes as shown in Fig. 6a; this is an indication that the gold electrodes were modified with the MnPcs complexes, hence preventing the oxidation of Au. From Fig. 6b, the MnTDMPc-gold electrode showed more blocking for UPD of copper than MnTBMPc-gold electrode. The latter still has a $\mathrm{Cu}^{2+} / \mathrm{Cu}$ anodic peak at around $0.1 \mathrm{~V}$. This anodic peak can be said to be negligible compared to that obtained at bare gold electrodes but comparing both of the modified electrodes, the more blocking characteristic of the MnTDMPc could be due to the influence of the ring substituents; the long $\mathrm{C}_{12} \mathrm{H}_{25}$ alkyl chain of the MnTDMPc is expected to have more blocking characteristics than the $\mathrm{C}_{6} \mathrm{H}_{5} \mathrm{CH}_{2}$ group of the MnTBMPc. Both MnTBMPc- and MnTDMPc-gold electrodes (Fig. 6c) clearly inhibited the $\left[\mathrm{Fe}\left(\mathrm{H}_{2} \mathrm{O}\right)_{6}\right]^{3+} /\left[\mathrm{Fe}\left(\mathrm{H}_{2} \mathrm{O}\right)_{6}\right]^{2+}$ redox reaction judging by the disappearance of $\mathrm{Fe}^{3+} / \mathrm{Fe}^{2+}$ anodic and cathodic peaks which appeared at the bare gold electrode (curve i, Fig. 6c). The surface concentrations of the complexes on gold electrodes were estimated using the charge difference between the bare gold $\left(\mathrm{Q}_{\text {Bare }}\right)$ and the MnPcs-SAMs $\left(\mathrm{Q}_{\text {sam }}\right)$ (Fig. 6a) and they were found to be $0.69 \times 10^{-10} \mathrm{~mol} \mathrm{~cm}^{-2}\left(241\right.$ molecules $\left.\AA^{-2}\right)$ and $0.78 \times 10^{-10} \mathrm{~mol} \mathrm{~cm}{ }^{-2}\left(213\right.$ molecules $\left.\AA^{-2}\right)$, respectively. These values are within the range for monolayer coverage. The cyclic voltammograms of the MnPcs modified gold electrodes in phosphate buffer $\mathrm{pH} 4$ is shown in Fig. 7. Broad anodic peaks were observed at 0.35 and $0.2 \mathrm{~V}$ for MnTBMPc- and MnTDMPc-SAM gold electrodes, respectively. These peaks correspond to the $\mathrm{Mn}^{\mathrm{IV}} / \mathrm{Mn}^{\mathrm{III}}$ processes, they are more easily observed for MnPc-SAM when compared to solution electrochemistry in Fig. 3. 

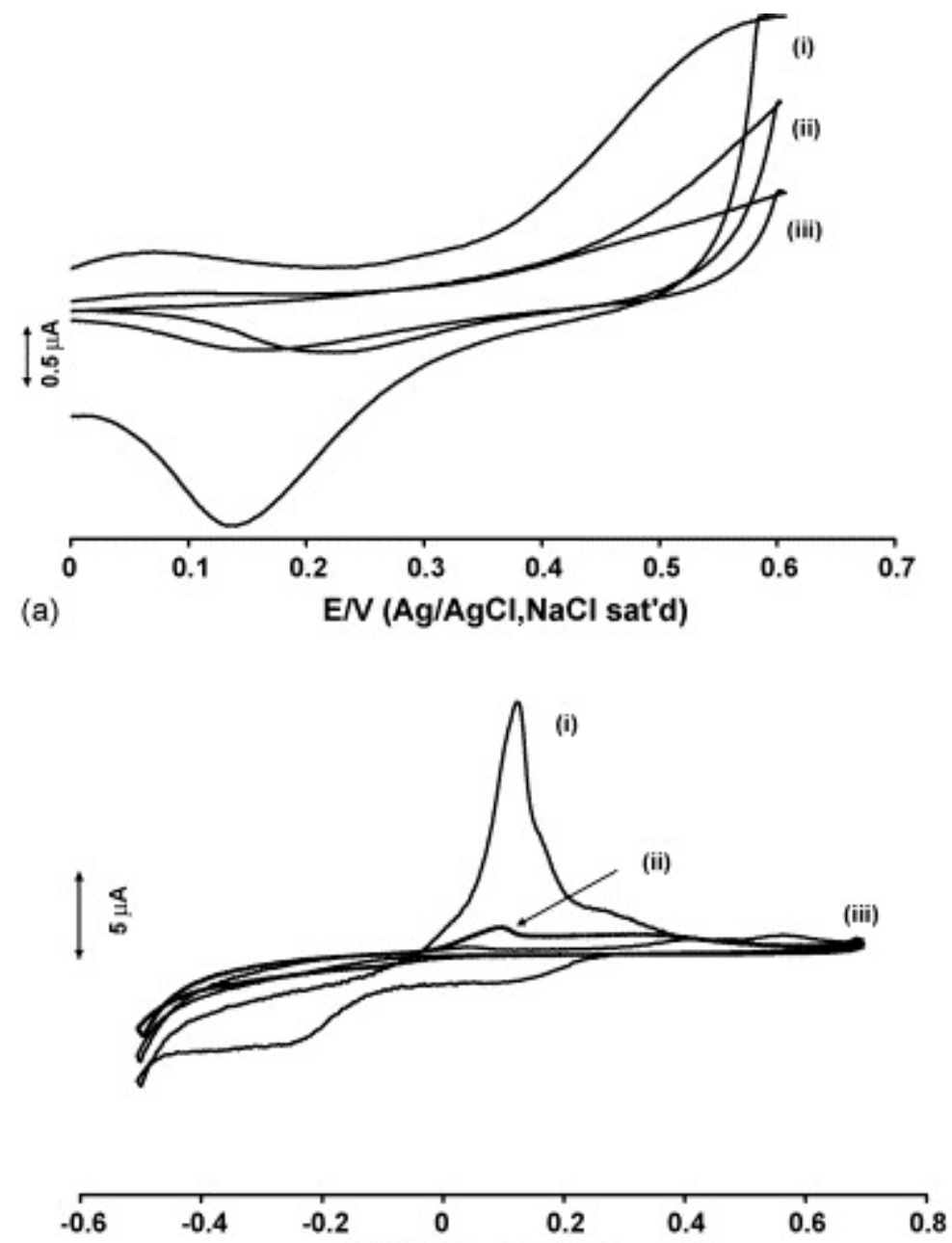

(b) $\mathrm{E} / \mathrm{V}(\mathrm{Ag} / \mathrm{AgCl}, \mathrm{NaCl}$ sat'd)

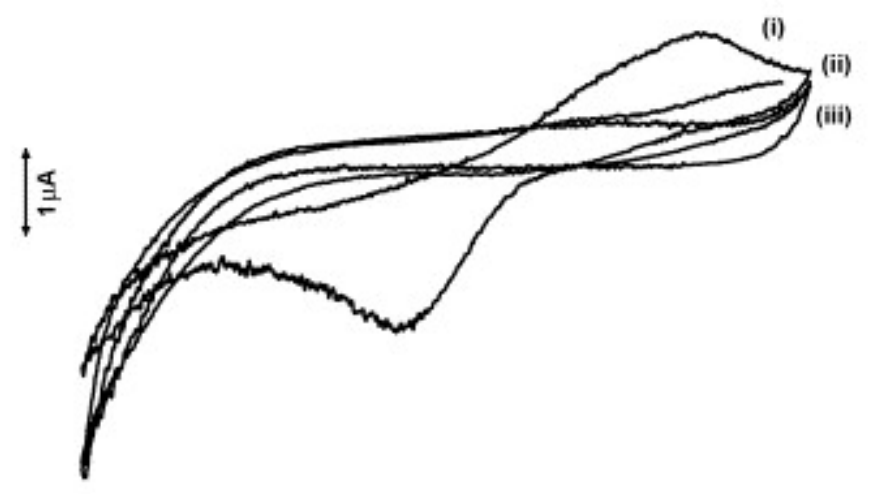

(c)

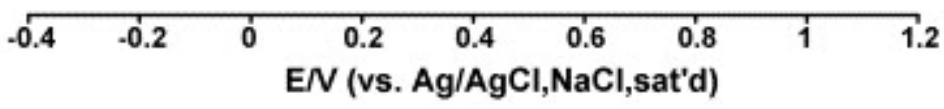

Fig. 6. Typical cyclic voltammograms of: (a) $10 \mathrm{mM} \mathrm{KOH}$, (b) UPD of $1 \mathrm{mM} \mathrm{CuSO}_{4}$ in $0.5 \mathrm{M} \mathrm{H}_{2} \mathrm{SO}_{4}$ and (c) $1 \mathrm{mM} \mathrm{Fe}\left(\mathrm{NH}_{4}\right)\left(\mathrm{SO}_{4}\right)_{2}$ in $1 \mathrm{mM} \mathrm{HClO}_{4}$ at: (i) bare gold electrode, 
(ii) MnTBMPc-SAM gold electrode, (iii) MnTDMPc-SAM gold electrode. Scan rate $=50 \mathrm{mV} / \mathrm{s}$.

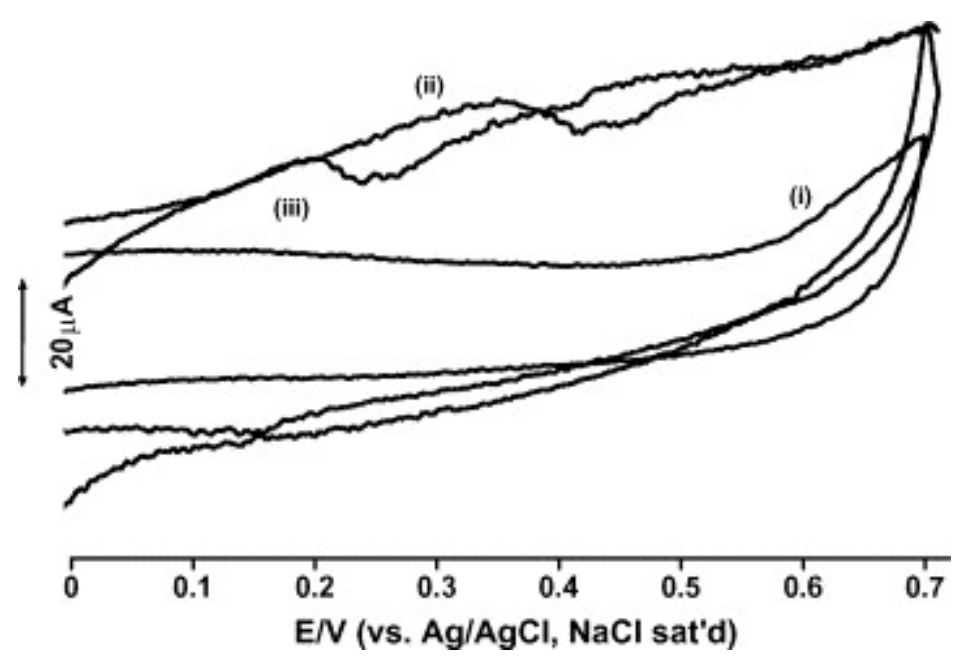

Fig. 7. Comparative cyclic voltammograms obtained at: (i) bare gold electrode, (ii) MnTBMPc-SAM gold electrode and (iii) MnTDMPc-SAM gold electrode in phosphate buffer $\mathrm{pH} 4$.

The MnPcs-SAM showed high stability within the $\mathrm{pH}$ of 2-9 in the potential window -0.2 to $+0.8 \mathrm{~V}$ versus $\mathrm{Ag} / \mathrm{AgCl} / \mathrm{NaCl}$ (saturated). The SAM of MnPcs complexes showed no detectable desorption both $\mathrm{pH} 4$ and 7 phosphate buffers when stored in the buffer solutions for over a month period.

\section{Conclusion}

The synthesis, spectroscopic and cyclic voltammetric characterisation of MnTBMPc and MnTDMPc complexes has been described. For each complex, three quasi reversible peaks were observed, one metal based and two ring based redox couples. Both complexes showed a broad and relatively small irreversible anodic peaks at around $+0.3 \mathrm{~V}$ which maybe due to $\mathrm{Mn}^{\mathrm{IV}} \mathrm{Pc}^{2-} / \mathrm{Mn}^{\mathrm{III}} \mathrm{Pc}^{2-}$ redox process. The complex MnTDMPc is easier to oxidize than the complex MnTBMPc and the other way around for oxidation. Spectroelectrochemistry confirmed redox couple (II) for both complexes as a metal based reduction of $\mathrm{Mn}{ }^{\mathrm{III}} \mathrm{Pc}$ to $\mathrm{Mn}{ }^{\mathrm{II}} \mathrm{Pc}$. Oxidation of the complexes resulted in decomposition. The complexes formed well packed and stable SAMs on gold electrodes which make them potential electrocatalysts and sensors for environmentally and biologically important molecules. 


\section{References}

[1] V. Iliev, A. Mihaylova and L. Biyarska, J. Mol. Catal. A: Chem. 184 (2002), p. 121.

[2] K. Ozoemena, N. Kutznetsova and T. Nyokong, J. Photochem. Photobiol. A: Chem. 139 (2001), p. 217.

[3] K. Ozoemena, N. Kutznetsova and T. Nyokong, J. Mol. Catal. A: Chem. 176 (2001), p. 29.

[4] J. Griffiths, J. Cruse-Sawyer, S.R. Wood, J. Schfield, S.B. Brown and B. Dixon, J. Photochem. Photobiol. B: Biol. 24 (1994), p. 195.

[5] E. Ben-Hur, R.C. Hoeben, H. Van Ormondt, T.M.A.R. Dubbleman and J. Van Stevenick, J. Photochem. Photobiol. B: Biol. 13 (1992), p. 145.

[6] H.S. Nalwa and J.S. Shirk In: C.C. Leznoff and A.B.P. Lever, Editors, Phthalocyanines: Properties and Applications 4, Wiley-VCH, New York (1996)

(Chapter 4).

[7] Z. Li, M. Lieberman and W. Hill, Langmuir 11 (2001), p. 4887.

[8] K. Ozoemena and T. Nyokong, Electrochim. Acta 47 (2002), p. 4035.

[9] K. Ozoemena, P. Westbroek and T. Nyokong, Electrochem. Commun. 3 (2001), p. 529.

[10] J. Obirai, N.P. Rodrigues, F. Bedioui and T. Nyokong, J. Porphyrins Phthalocyanines 7 (2003), p. 508.

[11] J. Obirai and T. Nyokong, Electrochim. Acta 49 (2004), p. 1417.

[12] J. Obirai and T. Nyokong, Electrochim. Acta 50 (2005), p. 3296.

[13] N. Periera Rodrigues, J. Obirai, T. Nyokong and F. Bedioui, Electroanalysis 17 (2005), p. 186.

[14] J. Obirai and T. Nyokong, Electrochim. Acta 50 (2005), p. 5427.

[15] M.J. Stillman and T. Nyokong In: C.C. Leznoff and A.B.P. Lever, Editors, Phthalocyanines: Properties and Applications vol. 1, VCH, New York (1989) (Chapter 3).

[16] D. Worhle, M. Eskes, K. Shigehara and A. Yamada, Synthesis (1993), p. 194. 
[17] A.G. Gürek and Ö. Bekaroğlu, J. Chem. Soc. Dalton Trans. (1994), p. 1419.

[18] M. Krejčik, M. Daněk and F. Hartl, J. Electroanal. Chem. 317 (1991), p. 179.

[19] C.C. Leznoff, L.S. Black, A. Hiebert, P.W. Causey, D. Christendat and A.B.P. Lever, Inorg. Chim. Acta 359 (2006), p. 2690.

[20] B. Agboola, K.I. Ozoemena and T. Nyokong, Electrochim. Acta 51 (2006), p. 4379.

[21] B.O. Agboola, K.I. Ozoemena and T. Nyokong, Electrochim. Acta 51 (2006), p. 6470.

[22] A. Louati, M. El Meray, J.J. Andre, J. Simon, K.M. Kadish, M. Gross and A. Giraudeau, Inorg. Chem. 24 (1985), p. 1175.

[23] D. Worhle and V. Schmidt, J. Chem. Soc. Dalton Trans. (1988), p. 549.

[24] J. Mack and M.J. Stillman, J. Porphyrins Phthalocyanines 5 (2001), p. 67.

[25] M.J. Stillman In: A.B.P. Lever and C.C. Leznoff, Editors, Phthalocyanines: Properties and Applications 3, VCH Publishers, New York (1993), p. 227 (Chapter 5).

[26] K. Takahashi, M. Kawashima, Y. Tomita and M. Itoh, Inorg. Chim. Acta 232 (1995), p. 69.

[27] K.V. Gothelf, J. Electroanal. Chem. 494 